\title{
Atypical Presentation of Syphilis in an HTLV-I Infected Patient
}

\author{
Dimas Carnaúba Jr., Achiléa Bittencourt \\ and Carlos Brites
}

\author{
Federal University of São Paulo, São Paulo, SP, \\ Brazil; Federal University of Bahia, Infectious \\ Diseases Foundation of Bahia, Salvador, Bahia, \\ Brazil
}

\begin{abstract}
We report the case of a 44 year-old female, who presented a long-lasting, clinically atypical, secondary syphilis ("malignant syphilis") in the right foot, which started six months before medical evaluation. The patient had a serological diagnosis of HTLV-I infection and syphilis two years before the onset of the skin lesions, following a blood donation. As she believed she was allergic to penicillin, she initially received sulfamethoxazole + trimethoprim, without any improvement of the clinical picture. After failure of this first treatment regimen, she was given penicillin, which promoted complete healing of the lesion. We found evidence that infection by HTLV-I is capable of modifying the clinical course of secondary syphilis.

Key Words: Secondary syphilis, HTLV-I infection; syphilis/HTLV-I coinfection; malignant syphilis.
\end{abstract}

Clinical manifestations of infection by human lymphotropic virus type I (HTLV-I) often include skin involvement, as seen in patients with infective dermatitis, severe forms of scabies, and adult T-cell leukemia/lymphoma [1-3]. It is also known that this agent can cause a variable degree of immune dysfunction, and this may modify the clinical presentation of infections [1,4-6].

Syphilis is a treponemal infection that, if not treated, can progress through four stages: primary (which usually is oligosymptomatic), secondary, and late, which includes central nervous system and cardiovascular involvement. Secondary syphilis is generally latent, but can present as a generalized and symmetrically distributed maculopapular rash, which typically involves palm and sole surfaces. [7].

Received on 13 December 2002; revised 30 July 2003.

Address for correspondence: Dr. Carlos Brites. Rua João das Botas, SN, 6o. Andar. Laboratório de Retrovírus, Canela, Salvador, Bahia, Brazil. Zip code: 40.155-020, Telephone: 55-712354866/235-4901.Fax:55-71-247-2756.E-mail:crbrites@ufba.br

The Brazilian Journal of Infectious Diseases 2003;7(4):273-277 (C) 2003 by The Brazilian Journal of Infectious Diseases and Contexto Publishing. All rights reserved.
Although there is experimental evidence showing that the clinical course of syphilis can be altered in animals infected by HTLV-I [8], we did not find any previous report of such interaction in human beings.

We report a case of a woman infected by HTLV-I, who developed an unusual presentation of secondary syphilis.

\section{Case Report}

A 44 year-old female teacher who lives in Maceió, the capital of Alagoas (a northeastern Brazilian state), asked for medical assistance for skin lesions in the upper face of her right foot, characterized by confluent, erythematous papules and plaques which started about six months before medical evaluation. She initially used a topical cream containing steroids, without any improvement. She had a serological diagnosis of HTLV-I two years before, following a blood donation. In addition, she had had a positive test for syphilis (VDRL=1:64), which was initially treated with sulfamethoxazole plus trimethoprim, since she reported allergy to penicillin. Serology for HIV-1 and hepatitis B were negative. She had never received blood products, and had no previous history of sexually transmitted diseases. 
Six months before the onset of the skin lesion, the patient presented with a vesicular eruption in the trunk, diagnosed as herpes virus infection, which was complicated by secondary bacterial infection. At that time, a CD $\mathrm{CD}_{4 / 8}$ measurement showed $990 \mathrm{CD}_{4}^{+}$cells/ $\mathrm{mm}^{3}$, and $656 \mathrm{CD}_{8}^{+}$cells $/ \mathrm{mm}^{3}$.

Dermatological examination: The patient presented confluent and erythematous papules and plaques, with small ulcers, on the dorsum of the right foot (Figure 1A), involving an area of $10 \times 12 \mathrm{~cm}$. Papules displaying these same characteristics were seen at the edges of the major lesions. She was initially diagnosed as having larvae migrans infection, and was treated with topical Thiabendazole. The lesion did not change with this treatment, and she was submitted to a biopsy, which revealed a pattern suggestive of secondary syphilis. The patient received 2,400,000 IU Benzathine Penicillin, intramuscularly, with a progressive improvement of the lesion, and complete healing after two months (Figure 1B).

Pathological report - The epidermis presented with hyperkeratosis and mild atrophy. Throughout the dermis, surrounding blood vessels, there was a perivascular and periadnexal infiltration of lymphocytes and plasma cells, sometimes associated with granulomatous reactions (Figures $2 \mathrm{~A}$ and 2B).

\section{Discussion}

Infection by HTLV-I causes neurological (HAM/ TSP), hematological (ATLL), and other types of diseases (infectious dermatitis, uveitis, pneumonitis, etc.) [9]. However, over than $90 \%$ of patients infected by HTLVI do not present any clinical symptoms. Nevertheless, some of these individuals show subclinical evidence of immune dysfunction, which can modify the course of some diseases, such as Strongyloides stercoralis infection, and others [4,10].

Syphilis is an ancient, well-known, sexually transmitted disease [7]. Although treatment of syphilis is simple and efficacious, in patients with severe forms of immunodeficiency (such as AIDS) it can be harder to control, and can cause more severe forms of disease, with frequent CNS involvement [11]. A severe form of secondary syphilis, called "malignant syphilis" can occur in HIV patients and in other immunodeficient conditions, presenting as papulo-vesicular, pustular and necrotizing lesions [12,13]. HTLV-I infection can cause some degree of immune dysfunction, and thus could modify the clinical course of syphilis.

The long lasting, localized and atypical eruption that we found in our patient is not a usual finding in secondary syphilis. However, the observed pattern of perivascular granulomatous reaction is typical of long-lasting secondary syphilis [14]. In an animal model, two out four rabbits infected with HTLV-I and Treponema pallidum presented with a protracted course of syphilis, when compared with those that were not infected with HTLV-I, which showed the usual course of infection, with rapid healing of skin lesions. One animal needed to be treated with penicillin after eight weeks of the challenge with $T$. pallidum, suggesting defective cell-mediated immunity [8].

The unusual manifestation of syphilis in our patient probably was a consequence of co-infection with HTLV-I. The only immunological evaluation she was submitted to showed a normal $\mathrm{CD}_{4 / 8}$ cell count, and a negative PPD test. These findings do not preclude immune dysfunction, since $\mathrm{CD}_{4 / 8}$ values are often normal, or even increased, in patients infected by HTLV-I, and a negative PPD test cannot be taken as conclusive evidence of an altered immune response.

In conclusion, we found evidence that infection by HTLV-I can modify the natural course of syphilis. The usual syphilis treatment regimen seems to works as well in co-infected patients.

\section{References}

1. Brites C., Weyll M., Pedroso C., et al. Severe and Norwegian scabies are strongly associated with retroviral infection, in Bahia, Brazil. The $1^{\text {st }}$ IAS Conference on HIV pathogenesis and treatment, July 8-11, 2001, Buenos Aires, Argentina.

2. Bittencourt A.L., Oliveira M.F. Infective dermatitis associated to HTLV-I - A review. An bras Dermatol 2001;76:723-32.

3. Whittaker S.J., Rustin Y.L., Levene G., et al. HTLV-1associated cutaneous disease: a clinicopathological and molecular study of patients from the U.K. Brit J Dermatol 1993; $128: 483-92$. 
Figure 1A. Confluent and erythematous papules and plaques on the dorsum of the right foot, some of them with shallow ulcers.



Figure 1B. Aspect of skin lesion in the right foot, after treatment.

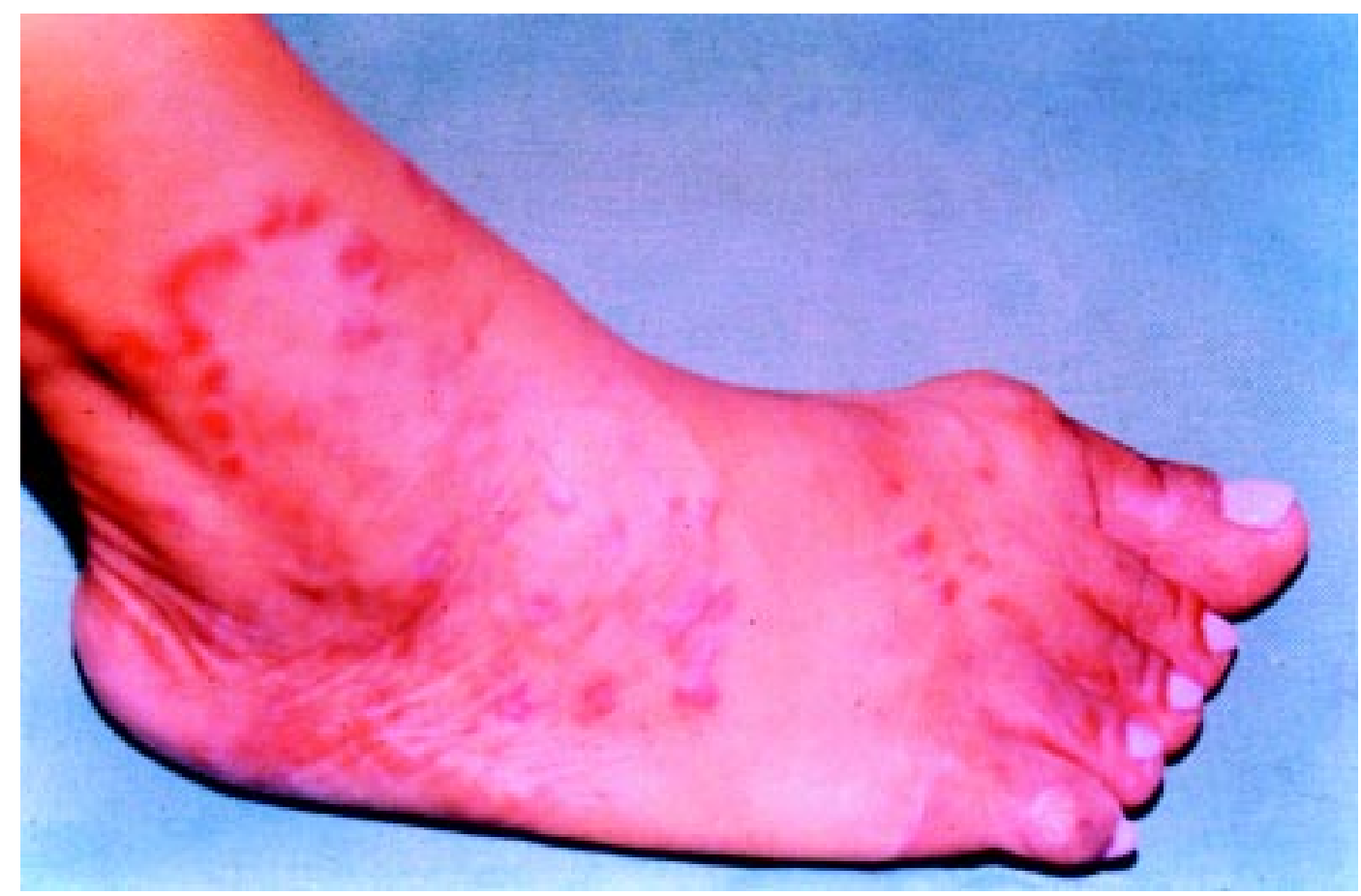


Figure 2A. Granulomatous reaction with epithelioid cells. HE, A 200.

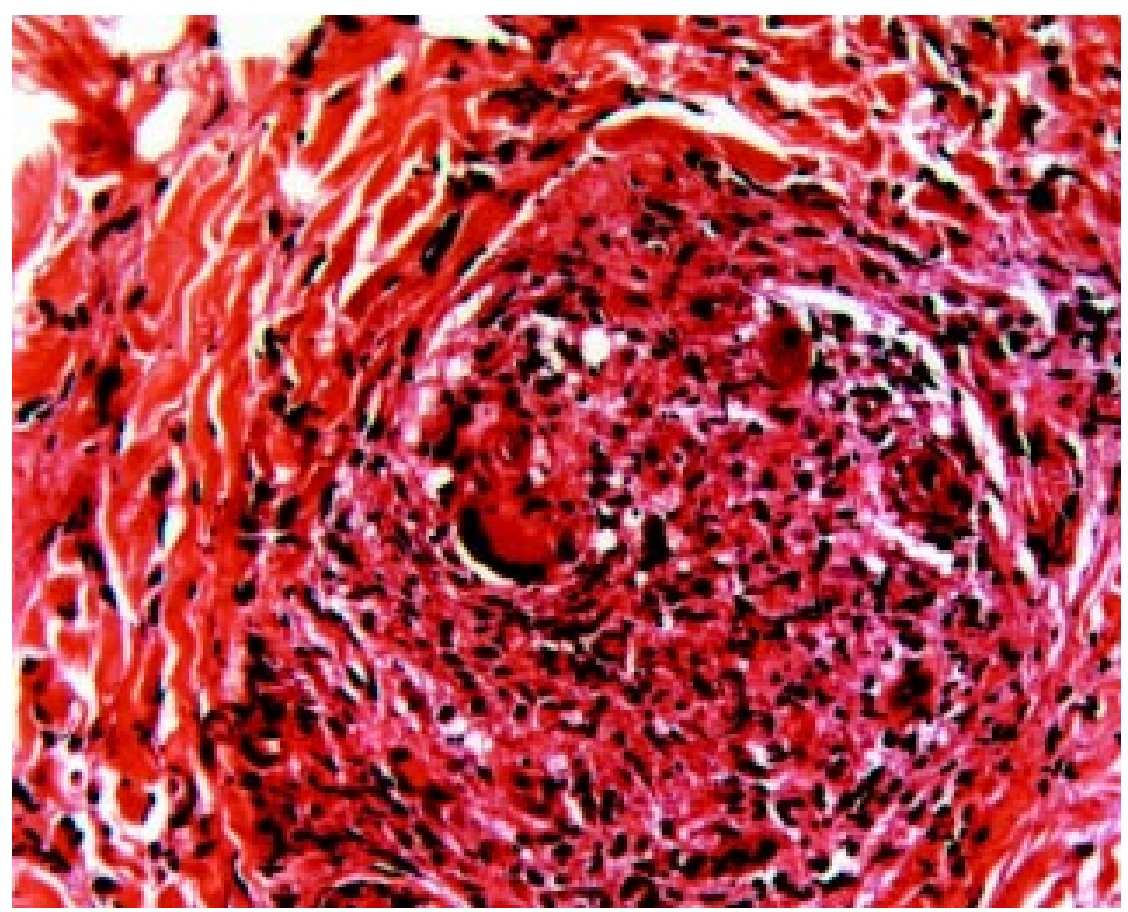

Figure 2B. A moderate perivascular and periadnexal infiltrate of lymphocytes and plasma cells in the deep dermis. HE, A 160.

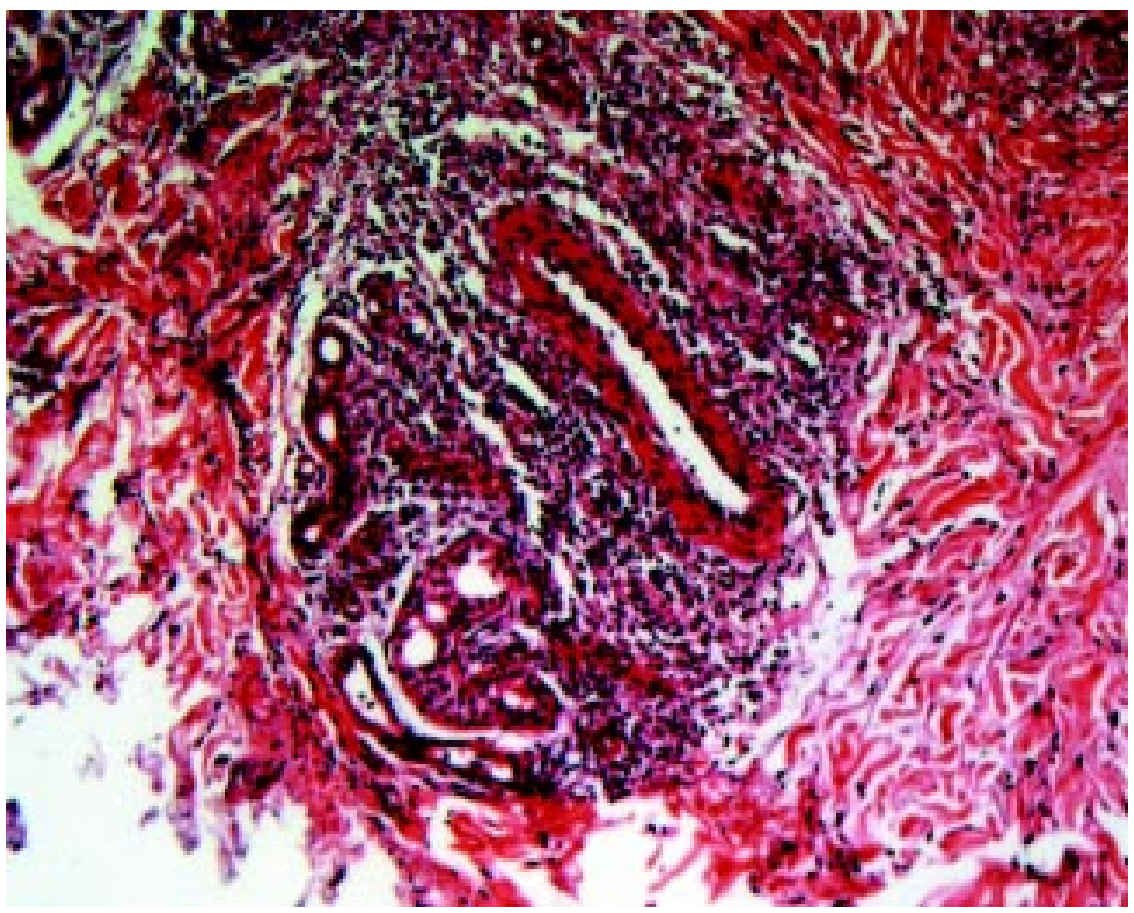


4. Carvalho E.M., Bacellar O., Porto A.F., et al. Cytokine profile and immunomodulation in asymptomatic HTLV1 infected blood donors. J AIDS. 2001;27:1-6.

5. Murai K., Tachibana N., Shiori S., et al. Suppression of delayed type hypersensitivity to PPD and PHA in elderly HTLV-I carriers. J Acq Immune Defic Syndr 1990;3:1006-9.

6. Newton R.C., Limpuangthip P., Greenberg S., et al. Strongyloidis stercoralis hyper infection in a carrier of HTLV-I virus with evidence of selective immune suppression. Am J Med 1992;92:202-8.

7. Morton R.S. The treponematoses. In: Champion RH, Bourton JL, Burns DA, Breathnach SM, eds. Rook/ Wilkinson/Ebling Textbook of dermatology, 6th ed., London. Blackwell Science 1998 p 1237-75.

8. Tseng C.K., Sell S. Protracted Teponema pallidumInduced Cutaneous Chancres in Rabbits Infected with Human T-cell Leukemia Virus Type I. AIDS Res Hum Retrovirol 1991;7:323-31.

9. Blattner W.A., Gallo R.C. Epidemiology of HTLV-I and HTLV-II infection. In Adult T-cell leukemia edited by K. Takatsuki, pp.91-112, Oxford. Oxford University Press 1994 p. 45-90.

10. Maciel E., Espinheira L., Brites C. Strongyloidis stercoralis as an opportunistic agent in a HAM/TSP patient. Braz J Infect Dis 1999;3(1):23-7.

11. Freire J.O., Siqueira A., Pedral-Sampaio D., et al. Syphilis is a herald disease for HIV in developing countries. The $1^{\text {st }}$ IAS Conference on HIV pathogenesis and treatment, July 8-11, 2001, Buenos Aires, Argentina.

12. Sterling J.C.S., Kurtz J.B. Viral infections. In: Champion RH, Bourton JL, Burns DA, Breathnach SM, eds. Rook/ Wilkinson/Ebling Textbook of dermatology, 6th ed., London. Blackwell Science 1998;995-1096.

13. Don P.C., Rubinstein R., Christie S. Malignant syphilis (lues maligna) and concurrent infection with HIV. Int. J. Dermatol 1995;34:403-07.

14. Crowson N.A., Magro C.M., Dumler S., et al. The treponemal and rickettsial diseases. In Barnhill RL. Textbook of Dermatopathology. New York, McGrawHill 1997;399-407. 